\title{
Structural Analysis and Comprehensive Evaluation of Economic Index of Distribution Network
}

\author{
Dong Litong*, Chen Yinghua, Ge Yanqin, Xu Xuesong \\ ${ }^{1}$ State Power Economic Research Institute, Beijing 100052, China
}

\begin{abstract}
With the orderly advancement of power system reform and the rapid development of incremental power distribution pilots, the investment process of power grid companies has become more and more transparent and standardized. However, in the current fierce environment, how to maintain certain economic benefits in various regional distribution networks has become a problem of concern. This paper establishes a distribution network asset economic index system from the three dimensions of investment cost, operating cost, and economic benefit. The hierarchical structure of indicators is clarified based on the interpretative structural model, and the economic level is measured based on the improved analytical hierarchy process AHP-fuzzy evaluation model. Finally, the analysis of calculation examples shows that: (1) The investment cost and operating cost of the distribution network indirectly affect the economic benefits of the power grid by affecting the electricity sales. (2) The economic levels of the distribution network in the three regions of $\mathrm{X}, \mathrm{Y}$, and $\mathrm{Z}$ are good, medium, and poor. The region $\mathrm{X}$ needs to strengthen the management of distribution network investment, and the region $\mathrm{Y}$ continues to improve the economy from all aspects of cost and income. The first thing in region $\mathrm{Z}$ is to improve the level of economic efficiency.
\end{abstract}

\section{Introduction}

With the acceleration of the construction of new infrastructure, there are more and more important power users such as high-precision manufacturing enterprises in urban areas. The residents' basic quality of life requirements are getting higher and higher. The construction of the domestic distribution network started late. At present, there are still many shortcomings in the distribution network in terms of distribution network structure, power supply reliability, distribution network automation, and unbalanced regional development [1-2]. However, the distribution network presents the characteristics of "multi-source", and new energy sources with fluctuating output such as wind power and photovoltaics urgently need to improve coordination [3]. Their access has a greater impact on the economics of the distribution network [4-5].

Scholars at home and abroad have constructed an evaluation index system from multiple perspectives such as economic benefits, safety level, and environmental protection to evaluate the operation of the distribution network [6-7]. When analyzing the internal influence relationship of indicators, the interpretation structure model is widely used, which can transform qualitative problems into quantitative problems [8]. When evaluating the comprehensive benefits of the distribution network, methods such as analytic hierarchy process and entropy weight method are usually used to calculate the index weights, and fuzzy evaluation methods, matter element extension models, etc. can be used to determine the development level of the distribution network [9-10]. The traditional analytic hierarchy process has the problem of consistency checking, this article uses the three-scale method to improve it [11-12].

This article only conducts an in-depth analysis of one aspect of the economics of the distribution network, builds an indicator system of the economics of the distribution network assets, analyzes the influence relationships of indicators based on the interpretation structure model, and determines the economic level of the distribution network based on the improved AHPfuzzy evaluation model.

\section{Economic index}

Lean management of power grid assets is mainly reflected in the distribution network link, and its economic level directly affects the vital interests of the power grid and users' electricity costs. The development of the distribution network is heavily influenced by external factors, coupled with a large number of equipment, which has the characteristics of small project scale and short construction period, and has higher requirements for lean management. There are also many differences in the development stage, electricity demand and electricity structure in various parts of our country. The development goals, construction standards, space resources, policy environment, and planning concepts of the distribution network are inconsistent. There are generally weak professional forces, poor related businesses, and technology. Problems such as weak

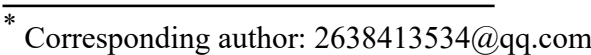


support means cannot meet the needs of building a modern distribution network with reasonable structure, advanced technology, flexibility, reliability, and costeffectiveness. Therefore, this paper establishes a general distribution network asset economic index system from the three dimensions of investment cost, operating cost, and economic benefit, as shown in figure 1. Then, based on the interpretation structure model to analyze the index structure relationship, and based on the AHP-fuzzy evaluation model to evaluate the economic level of the distribution network, which is of great significance for evaluating the operation efficiency of the distribution network and improving the lean level of the distribution network management.

\begin{tabular}{c|c|cc}
\hline \multirow{4}{*}{ Distribution } & Investment & S1 & Annual investment cost \\
& cost & S2 & Investment cost of each voltage level \\
network & S1 & S3 & Substation cost per unit capacity \\
\cline { 2 - 4 } & Operating & S5 & Annual operation and maintenance costs \\
economy & costs & S6 & Annual overhaul cost \\
A & B2 & S8 & Annual breakdown cost \\
\cline { 2 - 4 } & \multirow{2}{*}{ Economic } & S9 & Eecommissioning disposal costs \\
\hline & benefit & S10 & Electricity sales quantity sales revenue \\
& B3 & S12 & Unit investment increase power supply \\
& & S13 & Unit investment increase load supply \\
\hline
\end{tabular}

Fig. 1. Distribution network economic index system.

The investment cost index mainly refers to the expenses incurred during the construction and expansion of the distribution network. The higher the value of this index, the worse the economy of the distribution network. The operating cost index mainly refers to the cost of fault handling and equipment maintenance of the distribution network. The higher the value of this index, the worse the economy of the distribution network. The economic benefit index mainly refers to the economic benefits brought by the operation of the distribution network. The higher the index, the better the economy of the distribution network.

\section{Analysis of structure}

\subsection{Interpretative structural model}

There are many differences in the development stage and operation efficiency of distribution network in China. The regional evaluation index system is constructed from three dimensions of investment cost, operation cost and economic benefit. Each dimension contains multiple indicators, and the hierarchical structure relationship between indicators is complex. The use of interpretive structure model can transform the fuzzy structure system of indicators into intuitive levels.

Establish adjacency matrix. It is 1 when the two indicators have a direct influence relationship, and it is 0 when the two indicators have no direct influence relationship. The adjacency matrix $A$ of $n^{*} n$ is established.
Calculate reachability matrix is. When the integer $m$ is large enough to satisfy the following conditions:

$$
M=(I+A)^{m-1}=(I+A)^{m}=(I+A)^{m+1}
$$

Draw a hierarchical structure diagram of the economic indicators of distribution network assets. First determine the highest-level factors in the set, and then, regardless of the highest-level factors, determine the second-level factors in the remaining factor sets. Follow this step to cycle to clarify the factors at each level, thereby forming the inter-level division area.

$$
\begin{gathered}
R_{i}=\left\{S_{i} \in N \mid a_{i j}=1\right\} \\
T_{i}=\left\{S_{i} \in N \mid a_{j i}=1\right\} \\
R_{i}=R_{i} \cap T_{i}
\end{gathered}
$$

\subsection{Interpretation structure model of economic index of distribution network}

The adjacency matrix of economic indicators for distribution network is:

\begin{tabular}{|l|c|c|c|c|c|c|c|c|c|c|c|c|c|}
\hline & S1 & S2 & S3 & S4 & S5 & S6 & S7 & S8 & S9 & S10 & S11 & S12 & S13 \\
\hline S1 & 1 & 0 & 1 & 0 & 0 & 0 & 0 & 1 & 1 & 1 & 0 & 1 & 1 \\
\hline S2 & 0 & 1 & 0 & 1 & 0 & 0 & 0 & 1 & 1 & 1 & 0 & 1 & 1 \\
\hline S3 & 0 & 0 & 1 & 0 & 0 & 0 & 0 & 1 & 1 & 1 & 1 & 1 & 1 \\
\hline S4 & 0 & 0 & 0 & 1 & 0 & 0 & 0 & 1 & 1 & 1 & 1 & 1 & 1 \\
\hline S5 & 0 & 0 & 1 & 1 & 1 & 0 & 0 & 1 & 0 & 0 & 1 & 1 & 1 \\
\hline S6 & 0 & 0 & 0 & 0 & 1 & 1 & 1 & 1 & 0 & 0 & 1 & 0 & 0 \\
\hline S7 & 0 & 0 & 0 & 0 & 1 & 1 & 1 & 1 & 0 & 0 & 1 & 0 & 0 \\
\hline S8 & 0 & 0 & 0 & 0 & 0 & 0 & 0 & 1 & 0 & 0 & 1 & 0 & 0 \\
\hline S9 & 0 & 0 & 0 & 0 & 0 & 0 & 0 & 1 & 1 & 0 & 1 & 0 & 0 \\
\hline S10 & 0 & 0 & 0 & 0 & 0 & 0 & 0 & 1 & 0 & 1 & 1 & 0 & 0 \\
\hline S11 & 0 & 0 & 0 & 0 & 0 & 0 & 0 & 1 & 0 & 0 & 1 & 0 & 0 \\
\hline S12 & 0 & 0 & 1 & 1 & 0 & 0 & 0 & 1 & 1 & 1 & 1 & 1 & 0 \\
\hline S13 & 0 & 0 & 1 & 1 & 0 & 0 & 0 & 1 & 1 & 1 & 1 & 1 & 1 \\
\hline
\end{tabular}

The reachable matrix and sorted order of the economic indicators of the distribution network assets are:

\begin{tabular}{|c|c|c|c|c|c|c|c|c|c|c|c|c|c|}
\hline & S1 & S2 & S3 & S4 & S5 & S6 & S7 & S8 & S9 & S10 & S11 & S12 & S13 \\
\hline S1 & 1 & 0 & 1 & 1 & 0 & 0 & 0 & 1 & 1 & 1 & 1 & 1 & 1 \\
\hline S2 & 0 & 1 & 1 & 1 & 0 & 0 & 0 & 1 & 1 & 1 & 1 & 1 & 1 \\
\hline S3 & 0 & 0 & 1 & 1 & 0 & 0 & 0 & 1 & 1 & 1 & 1 & 1 & 1 \\
\hline S4 & 0 & 0 & 1 & 1 & 0 & 0 & 0 & 1 & 1 & 1 & 1 & 1 & 1 \\
\hline S5 & 0 & 0 & 1 & 1 & 1 & 0 & 0 & 1 & 1 & 1 & 1 & 1 & 1 \\
\hline S6 & 0 & 0 & 1 & 1 & 1 & 1 & 1 & 1 & 1 & 1 & 1 & 1 & 1 \\
\hline S7 & 0 & 0 & 1 & 1 & 1 & 1 & 1 & 1 & 1 & 1 & 1 & 1 & 1 \\
\hline S8 & 0 & 0 & 0 & 0 & 0 & 0 & 0 & 1 & 0 & 0 & 1 & 0 & 0 \\
\hline S9 & 0 & 0 & 0 & 0 & 0 & 0 & 0 & 1 & 1 & 0 & 1 & 0 & 0 \\
\hline S10 & 0 & 0 & 0 & 0 & 0 & 0 & 0 & 1 & 0 & 1 & 1 & 0 & 0 \\
\hline S11 & 0 & 0 & 0 & 0 & 0 & 0 & 0 & 1 & 0 & 0 & 1 & 0 & 0 \\
\hline S12 & 0 & 0 & 1 & 1 & 0 & 0 & 0 & 1 & 1 & 1 & 1 & 1 & 1 \\
\hline S13 & 0 & 0 & 1 & 1 & 0 & 0 & 0 & 1 & 1 & 1 & 1 & 1 & 1 \\
\hline
\end{tabular}




\begin{tabular}{|c|c|c|c|c|c|c|c|c|c|c|c|c|c|}
\hline & S8 & S11 & S9 & S10 & S3 & S4 & S12 & S13 & S1 & S2 & S5 & S6 & S7 \\
\hline S8 & 1 & 1 & 0 & 0 & 0 & 0 & 0 & 0 & 0 & 0 & 0 & 0 & 0 \\
\hline S11 & 1 & 1 & 0 & 0 & 0 & 0 & 0 & 0 & 0 & 0 & 0 & 0 & 0 \\
\hline S9 & 1 & 1 & 1 & 0 & 0 & 0 & 0 & 0 & 0 & 0 & 0 & 0 & 0 \\
\hline S10 & 1 & 1 & 0 & 1 & 0 & 0 & 0 & 0 & 0 & 0 & 0 & 0 & 0 \\
\hline S3 & 1 & 1 & 1 & 1 & 1 & 1 & 1 & 1 & 0 & 0 & 0 & 0 & 0 \\
\hline S4 & 1 & 1 & 1 & 1 & 1 & 1 & 1 & 1 & 0 & 0 & 0 & 0 & 0 \\
\hline S12 & 1 & 1 & 1 & 1 & 1 & 1 & 1 & 1 & 0 & 0 & 0 & 0 & 0 \\
\hline S13 & 1 & 1 & 1 & 1 & 1 & 1 & 1 & 1 & 0 & 0 & 0 & 0 & 0 \\
\hline S1 & 1 & 1 & 1 & 1 & 1 & 1 & 1 & 1 & 1 & 0 & 0 & 0 & 0 \\
\hline S2 & 1 & 1 & 1 & 1 & 1 & 1 & 1 & 1 & 0 & 1 & 0 & 0 & 0 \\
\hline S5 & 1 & 1 & 1 & 1 & 1 & 1 & 1 & 1 & 0 & 0 & 1 & 0 & 0 \\
\hline S6 & 1 & 1 & 1 & 1 & 1 & 1 & 1 & 1 & 0 & 0 & 1 & 1 & 1 \\
\hline S7 & 1 & 1 & 1 & 1 & 1 & 1 & 1 & 1 & 0 & 0 & 1 & 1 & 1 \\
\hline Draw
\end{tabular}

Draw hierarchical structure diagram according to the reachable matrix, as shown in Figure 2:

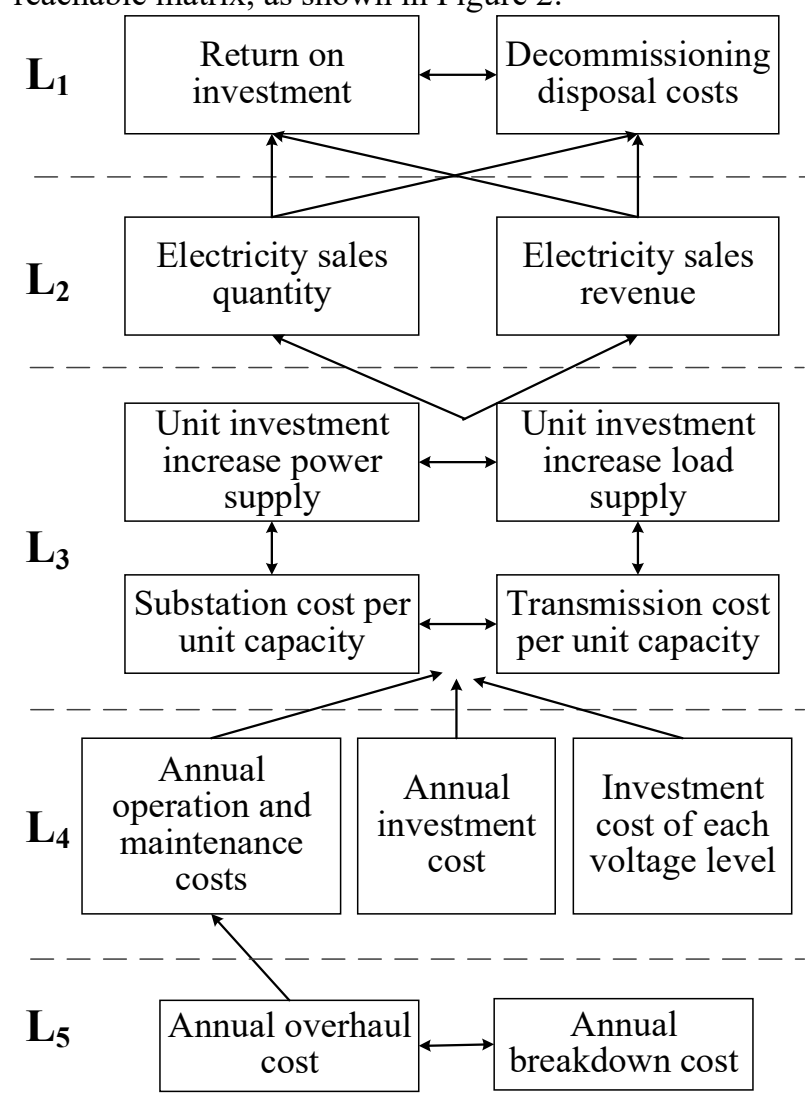

Fig. 2. Hierarchical structure diagram.

Figure 2 shows the hierarchical structure of the 13 indicators, which are divided into five levels. The operating cost indicators and investment cost indicators of the bottom layer L4 and L5 affect the cost of power transformation and transmission per unit capacity, and then the influence relationship of economy is transmitted to the unit investment, increased power supply and load, until the economic benefit index of the last level. It is of great significance to clarify the structural relationship of indicators for evaluating the economy of distribution network.

\section{Evaluation of economic benefit}

When using traditional AHP to calculate weights, decisions cannot be made because the judgment matrix does not meet the consistency test. In addition, there are many influencing factors in a complex system, and the workload of frequently adjusting the judgment matrix is too large. Therefore, AHP is improved. Use three-scale theory to build index comparison matrix:

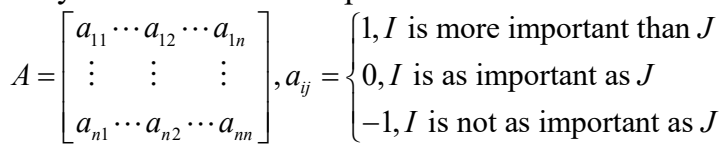

Establish the optimal transfer matrix and the comprehensive judgment matrix:

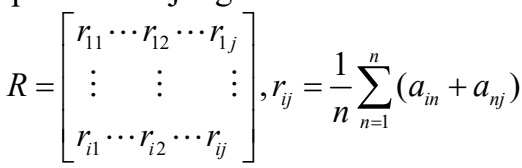

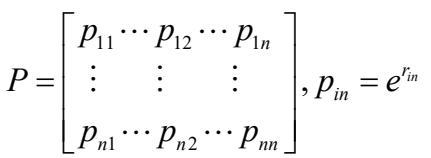

The product square root is used to calculate the weight:

$$
w=\left(w_{1}, w_{2}, \cdots, w_{n}\right), w_{i}=\left(\Pi d_{i n}\right)^{1 / n} / \sum_{n=1}^{n}\left(\Pi d_{i n}\right)^{1 / n}
$$

\subsection{Economic fuzzy evaluation model of distribution network}

Fuzzy comprehensive evaluation is a method to quantify factors that are not easy to quantify and fuzzy boundaries by using the principle of fuzzy relationship synthesis, and to judge and analyze the evaluation results of the evaluation object based on the membership levels of multiple factors.

Create a set of factors. According to the scope and level of the evaluation object, a hierarchical evaluation index system is established. The collection of elements in the factor layer in the index system constitutes the factor set $U=\left\{U_{1}, U_{2}, \cdots, U_{n}\right\}$.

Create a comment set. The evaluation level is determined based on the specific situation of the evaluation object, the number of levels and the range setting. It is assumed that $\mathrm{N}$ evaluation levels are given, and each level standard is an interval number.

Construct a fuzzy relationship matrix. The fuzzy relationship matrix is the membership degree matrix, which quantifies each index of the evaluation object in turn. The matrix represented by the degree of membership has a value range of $[0,1]$.

Use fuzzy matrix synthesis operations. The relationship between the evaluation index and the comment set is obtained through synthetic calculation. According to the principle of maximum membership degree, the level corresponding to the maximum value in $\mathrm{B}$ is taken as the economic benefit evaluation result of the distribution network.

$$
B=w \square R
$$

\subsection{Improved AHP}




\subsection{Economic evaluation results of distribution network}

Obtain the economic evaluation index data of the distribution network in three different areas of the city through fund collection research and consulting power companies, and evaluate the economics of the distribution network in different regions. Experts, engineers, and professors from power systems, distribution network planning, economic and technological research institutes, colleges and universities, etc. are invited to determine the judgment matrix of the importance of characterization indicators based on senior experience, as shown in figure 3.

\begin{tabular}{|c|c|c|c|c|c|c|c|c|c|c|c|c|c|}
\hline A & B1 & B2 & B3 & B4 & B5 & B6 & B7 & B8 & B9 & B10 & B11 & B12 & B13 \\
\hline B1 & 0 & 1 & 1 & -1 & 1 & 1 & 1 & 1 & -1 & -1 & -1 & -1 & -1 \\
\hline B2 & -1 & 0 & 1 & -1 & 1 & 1 & 1 & 1 & -1 & -1 & -1 & -1 & -1 \\
\hline B3 & -1 & -1 & 0 & -1 & 1 & 1 & 1 & -1 & -1 & -1 & -1 & -1 & -1 \\
\hline B4 & 1 & 1 & 1 & 0 & 1 & 1 & 1 & 1 & -1 & -1 & -1 & -1 & -1 \\
\hline B5 & -1 & -1 & -1 & -1 & 0 & -1 & -1 & -1 & -1 & -1 & -1 & -1 & -1 \\
\hline B6 & -1 & -1 & -1 & -1 & 1 & 0 & -1 & -1 & -1 & -1 & -1 & -1 & -1 \\
\hline B7 & -1 & -1 & -1 & -1 & 1 & 1 & 0 & -1 & -1 & -1 & -1 & -1 & -1 \\
\hline B8 & -1 & -1 & 1 & -1 & 1 & 1 & 1 & 0 & -1 & -1 & -1 & -1 & -1 \\
\hline B9 & 1 & 1 & 1 & 1 & 1 & 1 & 1 & 1 & 0 & -1 & -1 & 1 & 1 \\
\hline B10 & 1 & 1 & 1 & 1 & 1 & 1 & 1 & 1 & 1 & 0 & 1 & 1 & 1 \\
\hline B11 & 1 & 1 & 1 & 1 & 1 & 1 & 1 & 1 & 1 & -1 & 0 & 1 & 1 \\
\hline B12 & 1 & 1 & 1 & 1 & 1 & 1 & 1 & 1 & -1 & -1 & -1 & 0 & 0 \\
\hline B13 & 1 & 1 & 1 & 1 & 1 & 1 & 1 & 1 & -1 & -1 & -1 & 0 & 0 \\
\hline
\end{tabular}

Fig. 3. Judgment matrix.

According to the judgment matrix in Table 2, the index weight is calculated as $\mathrm{w}=(0.066,0.056,0.041$, $0.076,0.026,0.030,0.035,0.048,0.121,0.165,0.141,0.096$, 0.096). The above experts, etc., are requested to establish the classification standard of index data, as shown in Table 1. Then, the membership degree of each index of distribution network economy in different regions is scored, and the judgment matrix is obtained, as shown in Table 2, 3, 4 .

Table 1. Index classification table.

\begin{tabular}{|c|c|c|c|}
\hline Excellent (E) & Good (G) & Moderate (M) & Poor (P) \\
\hline$[90,100]$ & {$[81,90]$} & {$[61,80]$} & {$[0,60]$} \\
\hline
\end{tabular}

Table 2. Judgment matrix of membership of X.

\begin{tabular}{|c|c|c|c|c|}
\hline \multirow{2}{*}{ Index } & \multicolumn{4}{|c|}{$\mathrm{X}$} \\
\cline { 2 - 5 } & $\mathrm{E}$ & $\mathrm{G}$ & $\mathrm{M}$ & $\mathrm{P}$ \\
\hline S1 & 0.25 & 0.375 & 0.25 & 0 \\
\hline S2 & 0.3 & 0.5 & 0.2 & 0.3 \\
\hline S3 & 0.3 & 0.4 & 0.2 & 0.1 \\
\hline S4 & 0.1 & 0.375 & 0.4 & 0.3 \\
\hline S5 & 0.25 & 0.5 & 0.25 & 0 \\
\hline S6 & 0.25 & 0.5 & 0.25 & 0 \\
\hline S7 & 0.25 & 0.375 & 0.25 & 0.25 \\
\hline S8 & 0 & 0.625 & 0.25 & 0.125 \\
\hline S9 & 0.25 & 0.25 & 0.5 & 0 \\
\hline S10 & 0.25 & 0.5 & 0.25 & 0 \\
\hline S11 & 0.45 & 0.55 & 0 & 0.15 \\
\hline S12 & 0 & 0.2 & 0.6 & 0 \\
\hline S13 & 0.35 & 0.45 & 0.2 & 0 \\
\hline
\end{tabular}

Table 3. Judgment matrix of membership of Y. Index

\begin{tabular}{|c|c|c|c|c|}
\hline & E & G & M & P \\
\hline S1 & 0.125 & 0.25 & 0.375 & 0.25 \\
\hline S2 & 0.1 & 0.25 & 0.45 & 0.2 \\
\hline S3 & 0.3 & 0.4 & 0.2 & 0.1 \\
\hline S4 & 0.1 & 0.375 & 0.4 & 0.125 \\
\hline S5 & 0 & 0.25 & 0.5 & 0.25 \\
\hline S6 & 0 & 0.4 & 0.4 & 0.2 \\
\hline S7 & 0.25 & 0.375 & 0.25 & 0.125 \\
\hline S8 & 0 & 0.425 & 0.45 & 0.125 \\
\hline S9 & 0 & 0.25 & 0.6 & 0.15 \\
\hline S10 & 0 & 0.3 & 0.4 & 0.3 \\
\hline S11 & 0.1 & 0.55 & 0.35 & 0 \\
\hline S12 & 0 & 0.2 & 0.6 & 0.2 \\
\hline S13 & 0.35 & 0.45 & 0.2 & 0 \\
\hline
\end{tabular}

Table 4. Judgment matrix of membership of $Z$.

\begin{tabular}{|c|c|c|c|c|}
\hline \multirow{2}{*}{ Index } & \multicolumn{5}{|c|}{$\mathrm{Z}$} \\
\cline { 2 - 5 } & $\mathrm{E}$ & $\mathrm{G}$ & $\mathrm{M}$ & $\mathrm{P}$ \\
\hline S1 & 0 & 0.2 & 0.3 & 0.5 \\
\hline S2 & 0.3 & 0.5 & 0.2 & 0 \\
\hline S3 & 0.1 & 0.2 & 0.3 & 0.4 \\
\hline S4 & 0.3 & 0.2 & 0.4 & 0.1 \\
\hline S5 & 0 & 0.4 & 0.2 & 0.4 \\
\hline S6 & 0 & 0.35 & 0.15 & 0.5 \\
\hline S7 & 0.25 & 0.6 & 0.15 & 0 \\
\hline S8 & 0.125 & 0.125 & 0.25 & 0.5 \\
\hline S9 & 0 & 0.1 & 0.25 & 0.65 \\
\hline S10 & 0 & 0.1 & 0.15 & 0.75 \\
\hline S11 & 0.15 & 0.2 & 0.25 & 0.4 \\
\hline S12 & 0 & 0.2 & 0.6 & 0.2 \\
\hline S13 & 0 & 0.25 & 0.35 & 0.45 \\
\hline
\end{tabular}

According to the above weight vector and fuzzy matrix, the economic membership degree of the distribution network of $\mathrm{X}, \mathrm{Y}, \mathrm{Z}$ is calculated, as shown in Table 5. The level corresponding to the maximum degree of membership is the regional economic level of the distribution network, and the total score is calculated based on the upper limit of the interval. Figure 2 shows the scores of each dimension in the three regions of X, Y, and $\mathrm{Z}$.

Table 5. Membership of different regions.

\begin{tabular}{|c|c|c|c|c|c|}
\hline Regions & $\mathrm{E}$ & $\mathrm{G}$ & $\mathrm{M}$ & $\mathrm{P}$ & Score \\
\hline $\mathrm{X}$ & 0.2452 & 0.4228 & 0.2804 & 0.0516 & 88.1 \\
\hline $\mathrm{Y}$ & 0.0906 & 0.3483 & 0.4098 & 0.1513 & 82.3 \\
\hline $\mathrm{Z}$ & 0.0800 & 0.2134 & 0.2830 & 0.4285 & 75.6 \\
\hline
\end{tabular}

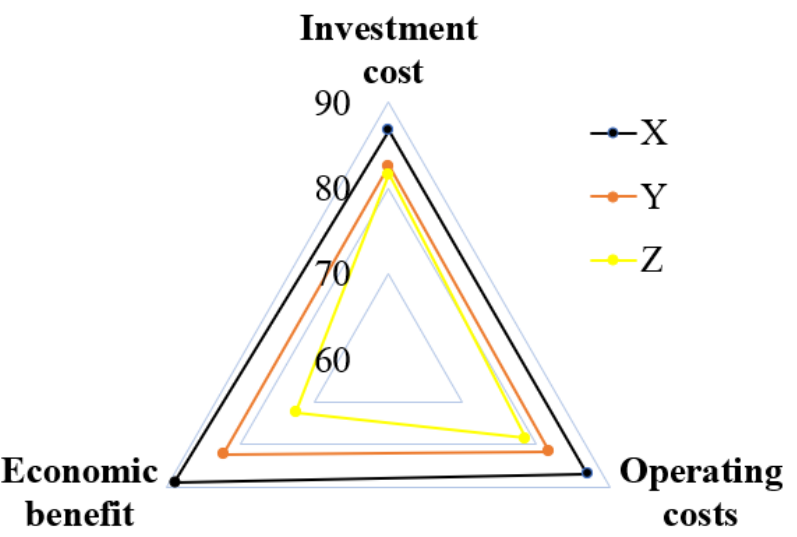

Fig. 4. Scores of each dimension of $X, Y$ and $Z$.

It can be seen from Table 5 and Figure 4 that the overall economic performance of the distribution network in region $\mathrm{X}$ is good. Among them, the economic benefit score is higher, and the investment cost score is lower. In the future, the level of refined management can 
be improved and the scale of distribution network investment can be reasonably controlled. The overall economic performance of the distribution network in region $\mathrm{Y}$ is moderate, with similar scores for investment costs, operating costs, and economic benefits. This shows that the development of the distribution network is balanced. There is no large investment, cost, and income imbalance. The distribution network in region $\mathrm{Z}$ has the worst economic performance, with the lowest economic benefit score. It is necessary to further strengthen the connection with the power supply special plan. Changing the wiring method, optimizing the grid structure can improve the utilization of transformers, lines and other equipment to increase electricity sales.

\section{Conclusion}

In view of the poor economic performance of distribution network in some areas, this paper constructs an index system from the three dimensions of investment cost, operation cost and economic benefit, determines the structural relationship of indicators based on the interpretative structural model, and clarifies the transmission relationship of influence factors. Then, aiming at the drawbacks of the one-time inspection, the AHP method is improved, and then the fuzzy comprehensive evaluation method is used to determine the economic subordination level of the distribution network. Finally, the conclusions are as follows: (1) The investment cost and operating cost of the distribution network are located at the bottom, which indirectly affects the economic benefits of the distribution network by affecting the electricity. (2) The economic levels of the distribution network in the three regions of $\mathrm{X}, \mathrm{Y}$, and $\mathrm{Z}$ are good, medium, and poor. The region $\mathrm{X}$ needs to strengthen the management of distribution network investment, and the region $\mathrm{Y}$ continues to improve the economy from all aspects of cost and income. Region $\mathrm{Z}$ can improve the utilization of equipment such as transformers and lines by changing the wiring method and optimizing the grid structure to ultimately achieve the goal of improving economic benefits.

\section{Acknowledgments}

Funding: State Grid Corporation of China Science and Technology Project "Research on comprehensive performance evaluation and equipment configuration optimization technology of distribution network asset life cycle management" (No: B3442019K001).

\section{Reference}

1. Liu, W.F., Xie, M.F. (2020) Economic Analysis of Renewable Energy in the Electricity Marketization Framework: A Case Study in Guangdong, China. Frontiers in Energy Research, 8.

2. Liu, H.F., Niu, D.X., Huang, Y.L., et al. (2016) Research on Distribution Network Development Speed Comprehensive Evaluation Method. In 2016
International Forum on Energy, Environment and Sustainable Development.

3. He, Y.J., Li, F., Wang, X.R., et al. (2019) Research on Instability of Distributed Renewable Energy Power Access to Distribution Network. In 2019 IEEE 3rd Information Technology, Networking, Electronic and Automation Control Conference (ITNEC).

4. Ehsan, A., Yang, Q. (2018) Optimal integration and planning of renewable distributed generation in the power distribution networks: A review of analytical techniques. Applied Energy, 210, 44-59.

5. $\mathrm{Hu}, \mathrm{L} .$, Hong, L., Zhenjian, X. (2016). Reliability evaluation method for active power distribution network based on switch boundary subarea division.

6. Ma L.Y., Wang Z.Q., Zhou T., et al. (2019) Evaluation Model for Economic Operation of Active Distribution Network Orienting to Energy Internet. JOURNAL OF ELECTRICAL ENGINEERING \& TECHNOLOGY, 14(3): 1151-1164.

7. Luo F.Z., Wei W., Wang C.S., et al. (2014) Research and application of GIS-based mediumvoltage distribution network comprehensive technical evaluation system. INTERNATIONAL TRANSACTIONS ON ELECTRICAL ENERGY SYSTEMS, 25(11): 2674-2684.

8. Han, Y.M., Zhu, Q.X., Geng, Z.Q. (2017) Energy and carbon emissions analysis and prediction of complex petrochemical systems based on an improved extreme learning machine integrated interpretative structural model. Applied Thermal Engineering, 115.

9. Yang, Y.-Y., Pan, F., Lin, G.-Y., et al. (2018) Comprehensive Evaluation of Distribution Network Reliability for Power Consumer Based on AHP and Entropy Combination Method. In 2018 International Conference on Power System Technology (POWERCON).

10. Wu, Q.L., Peng, C.Y. (2016). Comprehensive Benefit Evaluation of the Power Distribution Network Planning Project Based on Improved IAHP and Multi-Level Extension Assessment Method. Sustainability, 8(8), 1-18.

11. Li, J.B., Lu, M.S., Guo X.M., et al (2018) Insights into the improvement of alkaline hydrogen peroxide (AHP) pretreatment on the enzymatic hydrolysis of corn stover: Chemical and microstructural analyses. Bioresource Technology, 265.

12. Asmita, P., Xu., Y.J., Amit K. (2016) Corrigendum to "A note on "Applying fuzzy linguistic preference relations to the improvement of consistency of fuzzy AHP" ," [Information Sciences 346-347 (2016) 1-5][J]. Information Sciences,366. 